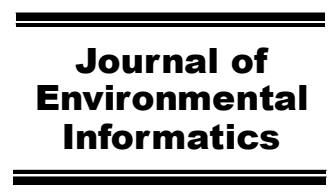

www.iseis.org/jei

\title{
Watershed-Scale Environmental Risk Assessment of Accidental Water Pollution: The Case of Laoguan River, China
}

\author{
R. Z. Liu ${ }^{1, *}$, K. Zhang ${ }^{1,2}$, Z. J. Zhang ${ }^{1}$, A. G. L. Borthwick ${ }^{3,4}$ \\ ${ }^{1}$ State Key Laboratory of Water Environment Simulation, School of Environment, Beijing Normal University, Beijing 100875, China \\ ${ }^{2}$ College of Civil Construction Engineering, Zhengzhou Institute of Aeronautical Industry Management, Zhengzhou 450015, China \\ ${ }^{3}$ School of Engineering, The Kings Buildings, The University of Edinburgh, Edinburgh EH9 3JL, U.K. \\ ${ }^{4}$ St Edmund Hall, Queen's Lane, Oxford OXI 4AR, U.K
}

Received 29 October 2014; revised 2 January 2016; accepted 2 February 2017; published online February 9, 2018

\begin{abstract}
Although co-existing sources of chemicals pose major cumulative environmental threats to watersheds, few risk assessments have specifically tackled the accidental chemical pollution of rivers at watershed-scale. Herein, a Watershed-scale Accidental Pollution Risk Assessment (WAPRA) method was constructed which applied a risk ranking procedure to the whole watershed, and was based on watershed-scale stressors, exposures to and effects of water accidental pollution risk (e.g., sudden occurrences, waterway spread, and acute consequences). Multi-criteria analysis and instantaneous water quality models were used to refine the risk ranking procedure within the framework of a Relative Risk Model (RRM), a regional-scale ecological risk assessment approach. The study area comprised the Laoguan River, a tributary watershed of the Danjiangkou Reservoir, which will eventually feed into the South-to-North Water Diversion Project in China. The resultant map shows that risk is higher in the upstream and downstream reaches, and lower in the middle reaches. The map also indicates that the greatest threat to water quality arises from the upstream heavy metal mine tailings ponds. Sensitivity and uncertainty analyses were performed to validate the robustness of the WAPRA method.
\end{abstract}

Keywords: water pollution accidents, risk analysis, watershed, South-to-North Water Diversion, Laoguan River

\section{Introduction}

Open waterways, such as rivers and lakes, are particularly susceptible to accidental pollution incidents. Over the past decade, the Ministry of Environmental Protection, P. R. China responded to 593 reported water pollution accidents (Ministry of Environmental Protection of People's Republic of China, $2004 \sim 2013$ ). These accidents comprised 55\% of the total number of environmental emergencies, the second most common being due to air pollution at 33\%. Relatively high levels of accidental water pollution events occur in both developing and developed countries according to National Response Center (2014). In China, recent water incidents include widespread chemical leaks across watersheds, which have caused severe environmental and socio-economic damage, including copperacid pollution of the Ting River in 2010, manganese pollution of the Fu River in 2011, cadmium pollution of the Long River in 2012, and phenylamine pollution of the Zhuozhang River in 2013. The foregoing chemical hazards (agents) occurred at watershed-scale, with the resulting exposures and hazard res-

\footnotetext{
${ }^{*}$ Corresponding author. Tel.: +86 105880 6679; fax: +86 1058806679 .

E-mail address: liurenzhi@bnu.edu.cn (R.Z. Liu)
}

ISSN: 1726-2135 print/1684-8799 online

C) 2018 ISEIS All rights reserved. doi:10.3808/jei.201600346 ponses requiring analyses over large areas (see Suter, 2007). Since Hunsaker, Suter and colleagues suggested performing risk assessment at regional-scale (Hunsaker et al., 1990; Suter, 1990), a considerable number of risk assessments have been undertaken over large areas. Many watershed-scale risk assessments have addressed the cumulative pollution risks from pesticides (Faggiano et al., 2010; Macary et al., 2014), nitrogen and phosphorus (Wickham and Wade, 2002), heavy metals (Yi et al., 2011), and multiple toxic chemicals (Giupponi et al., 1999). Some risk assessments analyzed cumulative natural disaster risks from drought (Gómez Gómez and Pérez Blanco, 2012), erosion (Mutekanga et al., 2010; Ji et al., 2014), and other physical stressors. Others integrated the multiple risk sources of chemical, physical, and biological stressors that affect multiple endpoints within a watershed ecosystem (Wiegers et al., 1998; Walker et al., 2001; Gottardo et al., 2011; Chen et al., 2012). For large-scale areas, multi-criteria risk analyses have been performed using multi-criteria comprehensive assessment (Giupponi et al., 1999; Li et al., 2009, 2011; Huang et al., 2011; Fan and Huang, 2012), experience and expert-judgment (Uricchio et al., 2004; Petrosillo et al., 2010), and fuzzy aggregative risk assessment (Sadiq and Husain, 2005; Cai et al., 2009a, b). To the authors' knowledge, hardly any research has focused to date on risk assessments of accidental water pollution at watershed-scale.

Regional-scale (e.g. watershed-scale) risk assessments involve multiple hazard sources, multiple endpoints, and com- 
plex interactions between these components (Hunsaker et al., 1990; Landis and Wiegers, 1997). Unlike cumulative pollution risks, accidental pollution risks are obtained by estimating the probability and severity of hazardous pollutant spills at watershed-scale; each spill is abrupt, and involves large quantities of highly concentrated hazardous pollutants, which have acute and severe consequences to the water quality of a waterway (Wang et al., 1998; Hu, 2009). Bearing this in mind, we propose a Watershed-scale Accidental Pollution Risk Assessment (WAPRA) method to assist in the prevention of, or preparation for, water pollution incidents. The WAPRA method adopts an initial idea of risk ranking at regional-scale, adopted from the Relative Risk Model (RRM) originally proposed by Landis and Wiegers (1997) and Wiegers et al. (1998). The new method uses multi-criteria analysis and instantaneous water quality models to refine risk ranking within the RRM framework with the help of GIS tools. It estimates the relative risk experienced in each sub-area for a combination of multiple "source-habitat-impact" risk routes using the product of the hazard ranking of the source with the vulnerability ranking of the habitat instead of the much more difficult calculation of probability and severity for each route. The study area, Laoguan River is a typical main tributary watershed that discharges into Danjiangkou Reservoir, the source for the middle route of South-to-North Water Diversion Project in China. Proper water quality and aquatic safety of the Laoguan River are vital to the Danjiangkou Reservoir watershed. Using the WAPRA method, a risk map for the Laoguan River basin was generated. The resultant risk map identifies areas prone to the highest risk, locations of the most significant pollutant sources and the most vulnerable receptors, all of which are useful for decision-making in the context of watershed environmental risk management. More important is to find out the exact weaknesses, difficulties, and key locations for prevention and/or mitigation activities concerning acute water pollution accidents in the Laoguan River watershed. It is imperative that the water supply safety be guaranteed of the middle route of China's South-to-North Water Diversion Project which has been operational since December 12, 2014.

\section{Methodology and Materials}

\subsection{Principles behind Watershed-scale Risk Assessment}

In practice, a watershed-scale risk assessment deals with a complex environment wherein many "source-habitat-impact" risk routes co-exist in a network of multiple habitats with multiple sources of multiple stressors affecting multiple endpoints (see Landis and Wiegers, 1997 and Wiegers et al., 1998). According to the regional environmental risk system (Liu et al., 2013), any single risk route potentially leads to a water pollution accident that is deemed to have occurred when an environmental pollution hazard is triggered (i.e., sudden release of toxic chemicals or heavy metals), and when its residual impact on a vulnerable risk receptor (e.g., a water intake) is sufficient to cause damage. Stressors refer to a variety of hazardous pollutants (e.g., phenylamine or cadmium) abruptly released into a waterway. Sources of pollutants include chemical proce- ssing plants, heavy metal mine tailings ponds, and vehicles transporting chemicals. Habitats comprise water environment and affected entities such as residential land, agricultural land, and nature reserves. A single source or a single habitat may simultaneously involve a variety of risk routes (see Landis, 2005). For a single habitat, Source A and Source B pose a greater hazard than does merely Source A in terms of the spatially cumulative impacts (see Environmental Protection Agency, 2003). In particular, the more chemical industries are located in close proximity in the upstream sub-watershed, the higher the level of hazard (risk) that can potentially spread to a given water intake in a downstream sub-watershed. Herein, multiple sources that affect assessment endpoints are treated as additive at a spatial location (Landis and Wiegers, 1997). Large quantities of suddenly released, highly concentrated hazardous pollutants pose a cascade of pollution hazards reaching receptors one-by-one in the downstream direction (EPA, 2003; Huang and $\mathrm{CaO}, 2011)$. However, integration of these routes is best facilitated by the use of ranks (Landis, 2005), because of the incommensurable nature of the risks to the various entities and attributes in a watershed, along with the difficulty of quantifying numerous exposure-response relationships (Suter, 2007).

\subsection{Watershed-scale Risk Assessment}

Using the principles mentioned above, we develop a Watershed-scale Accidental Pollution Risk Assessment (WAPRA), adapted from the Relative Risk Model (RRM) framework (Landis, 2005). The WAPRA comprises five key steps: definition of sub-watersheds, analyses of stressors and receptors by multiple criteria, construction of the conceptual model, analyses of exposures and effects, calculation of a risk ranking for each sub-watershed. An uncertainty analysis is undertaken after the risk ranking has been established.

\subsubsection{Definition of Sub-watersheds}

Following the fate of precipitation in a watershed, the boundaries of the basic units for risk ranking may be delineated according to the sub watersheds. A single sub-watershed (risk region) incorporates appropriate sources, stressors, and habitats based on possible pathways of exposure in a spatial sense (Landis, 2005), where the endpoint that experiences the hazard might or might not be contained within the geographical area that produced the hazard (Hunsaker et al., 1990). Using the hydrological analysis function in ArcGIS tools, the flow networks and catchment basins are derived from a Digital Elevation Model (DEM) of the study area (Jenson and Domingue, 1988). Furthermore, the sub-watersheds are defined for risk ranking in combination with the locations of stressors (sources), receptors (habitats), and the pathways of exposure.

\subsubsection{Multi-criteria Analyses of Stressors and Receptors}

In a watershed, hazardous stressors typically arise from spills emanating from industrial enterprises and (heavy metal) mine tailings ponds. Herein, focusing on stationary stressors, we use a complete index system to evaluate the hazard degree 
within a mapping unit based on formulae derived by Liu et al., (2013). Considering the inherent hazard of stressors and the operability of assessment, simplified multiple criteria are then derived for the stressors' hazard analysis from the derived formulae, which have been adopted into a national guidebook (China MEP, 2014). The industrial enterprises hazard qualitatively describes the likelihood and severity of abrupt pollution occurrences, determined by the quantity of hazardous substances, production process safety, and risk control. Conventionally, a ranking matrix is used to evaluate the hazard level according to the quotient of stock quantity to threshold quantity of hazardous substances $(Q)$ and the level of management concerning production process and risk control $(M)$ (see Table 1). The ranking matrix is determined through much discussion, according to the ranking practices of over 40,000 national inspection records of Environmental Risk and Chemicals in Enterprises of Key Industries in China in 2010. Stock quantity refers to the total quantity of a hazardous substance involved in production and storage. The threshold quantity is obtained from a hazardous substance list (see AQSIQ, 2009). $Q$ is the sum of each single hazardous substance quotient. A linear combination of sub indicators is used to describe the management level concerning production process and risk control as follows: category of industry $\left(m_{1}\right)$, production process safety $\left(m_{2}\right)$, safety production control $\left(m_{3}\right)$, risk prevention and control $\left(m_{4}\right)$, environmental emergency plan $\left(m_{5}\right)$, wastewater discharge destination $\left(m_{6}\right)$, and hazardous wastewater discharge quantity $\left(m_{7}\right)$. The foregoing sub-indicators of $\mathrm{M}$ are derived from the risk investigation results for the relevant industrial enterprises. All sub-indicators are qualitatively descriptive and graded with values of $10,7.5,5$, and 2.5 following the procedure outlined in China MEP (2014). Therefore, $M$ is calculated from:

$M=\sum_{i=1}^{7} m_{i} w_{i}$

where $m_{i}$ and $w_{i}$ are the value and weight of the $i$-th sub-indicator. The weights are obtained by the Analytic Hierarchy Process (AHP) method (see Saaty, 1980) such that $w_{1}, w_{2}, \ldots, w_{7}$ have the following values: $0.095,0.250,0.095,0.314,0.055$, 0.119 , and 0.072 .

Table 1. Hazard Ranking Matrix for Industrial Enterprises

\begin{tabular}{lllll}
\hline \multirow{2}{*}{$Q$} & \multicolumn{4}{c}{$M$} \\
\cline { 2 - 5 } \multicolumn{1}{c}{$M \leq 1$} & 4 & $4<M \leq 6$ & $6<M \leq 8$ & $M>8$ \\
\hline $1 \leq Q<10$ & 6 & 6 & 4 & 4 \\
$10 \leq Q<100$ & 6 & 8 & 8 & 8 \\
$Q \geq 100$ & 8 & 8 & 8 & 8 \\
\hline
\end{tabular}

The mine tailings pond hazard is determined by means of the design grade $(\mathrm{G})$ and safety state $(\mathrm{S})$ of the tailings pond, obtained using the ranking matrix listed in Table 2 . The design grade $(\mathrm{G})$ is classed as being at first, second and third level by considering a combination of the storage capacity and the dam height according to safety regulations (SAWS, 2006). The safety state (S) involves the storage methods, storage time, and infrastructure reinforcement. The data have been collected from risk investigations into mine tailings ponds throughout the whole watershed.

Table 2. Hazard Ranking Matrix for Mine Tailings Ponds

\begin{tabular}{llll}
\hline \multirow{2}{*}{ S } & \multicolumn{3}{c}{$\mathrm{G}$} \\
\cline { 2 - 4 } & $\begin{array}{l}\text { First } \\
\text { level }\end{array}$ & $\begin{array}{l}\text { Second } \\
\text { level }\end{array}$ & $\begin{array}{l}\text { Third } \\
\text { level }\end{array}$ \\
\hline $\begin{array}{l}\text { Open storage } \\
\begin{array}{l}\text { Served for }>\text { 10 years or over the } \\
\text { service life }\end{array}\end{array}$ & 10 & 10 & 8 \\
$\begin{array}{l}\text { Served } 5 \sim 10 \text { years } \\
\begin{array}{l}\text { Served for }<5 \text { years or reinforced } \\
\text { during last 5 years }\end{array}\end{array}$ & 8 & 10 & 8 \\
\hline
\end{tabular}

Receptors that might potentially be exposed to a water pollution hazard comprise drinking water intakes, irrigation water intakes, water bodies, residential land, agricultural land, woodland, and nature reserves. Receptor vulnerability describes the levels susceptible to loss and damage, following Liu et al. (2013). The size and sensitivity of a receptor is used to rank its vulnerability in three grades, 6,4 , and 2 , in accordance with national criteria or expert judgment (see Table 3 ).

Table 3. Vulnerability Ranking Criteria of Risk Receptors

\begin{tabular}{|c|c|c|c|}
\hline Receptor & Criteria & Grade & Classification \\
\hline \multirow{3}{*}{$\begin{array}{l}\text { Drinking water } \\
\text { intakes }^{\mathrm{a}}\end{array}$} & \multirow{3}{*}{$\begin{array}{l}\text { Number of people } \\
\text { served }\end{array}$} & 2 & $0-50000$ \\
\hline & & 4 & $50000-100000$ \\
\hline & & 6 & $>100000$ \\
\hline \multirow{3}{*}{$\begin{array}{l}\text { Irrigating water } \\
\text { intakes }^{\mathrm{b}}\end{array}$} & \multirow{3}{*}{$\begin{array}{l}\text { Farming area served } \\
\left(\mathrm{km}^{2}\right)\end{array}$} & 2 & $0-100$ \\
\hline & & 4 & $100-200$ \\
\hline & & 6 & $>200$ \\
\hline \multirow{3}{*}{ Residential land ${ }^{a}$} & \multirow{3}{*}{$\begin{array}{l}\text { Population density } \\
\left(\text { Capita } / \mathrm{km}^{2}\right)\end{array}$} & 2 & $0-3500$ \\
\hline & & 4 & $3500-6000$ \\
\hline & & 6 & $>6000$ \\
\hline \multirow{3}{*}{ Agricultural land ${ }^{\mathrm{b}}$} & \multirow{3}{*}{ Type of crops } & 2 & $\begin{array}{l}\text { Green manure } \\
\text { crops }\end{array}$ \\
\hline & & 4 & Commercial crops \\
\hline & & 6 & Food crops \\
\hline \multirow{3}{*}{ Woodland ${ }^{b}$} & \multirow{3}{*}{ Type of woodland } & 2 & Shrub land \\
\hline & & 4 & Sparse woodland \\
\hline & & 6 & Forest land \\
\hline \multirow{3}{*}{ Water bodies ${ }^{c}$} & \multirow{3}{*}{$\begin{array}{l}\text { Environmental func- } \\
\text { tion zones }\end{array}$} & 2 & grades IV and V \\
\hline & & 4 & grade III \\
\hline & & 6 & grades I and II \\
\hline \multirow{3}{*}{ Nature reserves ${ }^{\mathrm{d}}$} & \multirow{3}{*}{ Function zones } & 2 & Test area \\
\hline & & 4 & Buffer area \\
\hline & & 6 & Central area \\
\hline
\end{tabular}

${ }^{a}$ According to the agglomeration effect of population density and the potential risk to resident safety based on empirical classification.

${ }^{\mathrm{b}}$ According to the potential risk to resident safety and economic loss of crops based on empirical classification.

c According to the environmental function zones of surface water (China SEPA, 2002). 
${ }^{\mathrm{d}}$ According to the zones of nature reserves (China SC, 1994).

\subsubsection{Construction of Conceptual Model}

A conceptual model (see Figure 1) is constructed to delineate all potential risk routes which connect sources (stressors), habitats (receptors), pathways (exposures), and endpoints, in each sub-watershed. Industrial enterprises and mine tailings ponds are introduced as two typical risk sources. Risk receptors exposed to stressors from hazardous water contaminants include drinking water intakes, irrigation water intakes, water bodies, and areas adjacent to waterways such as residential land, agricultural land, woodland, and the nature reserves. Focusing on the water environment and its collateral values [i.e. values of supplying drinking water (resident safety), irrigation water (property safety), and habitats (ecosystem health)], we select resident safety, property safety, water quality, and ecosystem health as the risk assessment endpoints of accidental water pollution. However, any single risk route may remain within the same sub-watershed or propagate through the entire watershed. With this in mind, we have screened and identified each effective risk route according to spatial locations of multiple sources and multiple receptors, and the effects of accidental water pollution.

\subsubsection{Exposure and Effect Analyses}

The conceptual model provides a basis by which to analyze exposure and effect in a single risk route. Following Wiegers et al. (1998), an exposure filter has been used to screen the source-receptor combinations likely to result in exposure, and an effect filter used to weight those combinations likely to affect a specific assessment endpoint. The filter consists of weighting factors $0,0.5$, or 1 indicating low, medium, or high probability, respectively. For any single risk route derived from the conceptual model, the exposure filter is assigned according to the probability that chemicals (released from the source) propagate to the receptor. The effect filter is assigned according to the probability that exposure to the receptor causes the effect to reach each endpoint. Instead of the conventional qualitative judgment, we use a simple instantaneous water quality model (a convection-diffusion model for an instantaneous point source) to simulate approximately the fate of chemicals and therefore estimate exposure probability:

$\frac{\partial C}{\partial t}+u \frac{\partial C}{\partial x}=E \frac{\partial^{2} C}{\partial x^{2}}$

where $C$ is the concentration of a chemical, $(\mathrm{mg} / \mathrm{l}) ; x$ is streamwise distance, $(\mathrm{m}) ; u$ is the average flow rate of the river, $(\mathrm{m} / \mathrm{s})$; $t$ is time, (s); and $E$ is the turbulent diffusion coefficient, $\left(\mathrm{m}^{2} / \mathrm{s}\right)$.

\subsubsection{Ranking Risk of Sub-watersheds}

The risk route score is calculated by multiplying together the hazard ranking $(H)$, vulnerability ranking $(V)$, exposure fil- ter $(E x)$, and effect filter (Ef) (see Wiegers et al., 1998; Liu et al., 2013). The relative risk score (RS) of a sub-watershed is obtained by integrating all risk routes which end within the same sub-watershed. Interval breaks of 500, 1000, and 1500 are used to rank the risk levels of the sub-watersheds as low, medium, high, and very high. The relative risk score is thus defined as:

$R S_{i}=\sum H_{i j} \times V_{i l} \times E x_{j l} \times E f_{l m}$

where $i$ is the sub-watershed series (sub-watershed 1, 2, 3, etc.), $j$ is the source series, $l$ is the receptor series, and $m$ is the endpoint series.

\subsubsection{Uncertainty Analysis}

The abovementioned risk scores are point estimates based on ranks and filters derived from imperfect data, which bring uncertainty into the assessment process (Landis, 2005). Monte Carlo analysis is used to generate a distribution of probable risk prediction for each sub-watershed instead of a point estimate (Fan et al., 2017). Initially, we assigned designations of low, medium, or high uncertainty to each source, receptor rank, exposure, and effects filter based on data quality and availability. Then we assigned discrete probability distributions to ranks and filters with medium and high uncertainty, and left those with low uncertainty simply as the original point estimates (Landis, 2005; Wang et al., 2018). Next Monte Carlo analysis combined assigned probability distributions of input variables (i.e. ranks and filters) to estimate a probability distribution for an output variable (i.e. the risk estimate) by 1000-iteration simulations using Crystal Ball ${ }^{\circledR} 2000$ software (Decisioneering, Inc., Denver, USA). The output distribution for each sub-watershed was used to quantify the effects of uncertainty in the input variables on the risk predictions. Finally, based on the results from the 1000 iterations, rank correlation coefficients of ranks and filters in each sub-watershed were generated by means of the widely used Spearman correlation analysis (or so-called sensitivity analysis) module in Crystal Ball ${ }^{\circledR} 2000$, where the higher the correlation coefficient is, the greater the contribution (or more sensitive) to the overall uncertainty.

\subsection{Study Area and Materials}

\subsubsection{Study Area}

Laoguan River is located in the southwest of Henan Province in China and flows through four counties (see Figure 2). Laoguan River has its origins in Luanchuan County and Lushi County, turns southeast and passes through Xixia County and Xichuan County, before finally entering the Danjiangkou reservoir. The river has total length of $255 \mathrm{~km}$, basin area of $4,219 \mathrm{~km}^{2}$, and natural fall in bed elevation of $1340 \mathrm{~m}$. The upstream sub-catchment in Lushi and Luanchuan occupies an area of $953 \mathrm{~km}^{2}$, possesses abundant metal mineral resources (e.g. molybdenum, gold, iron, and vanadium), and so faces a considerable pollution threat from its many heavy metal mine 


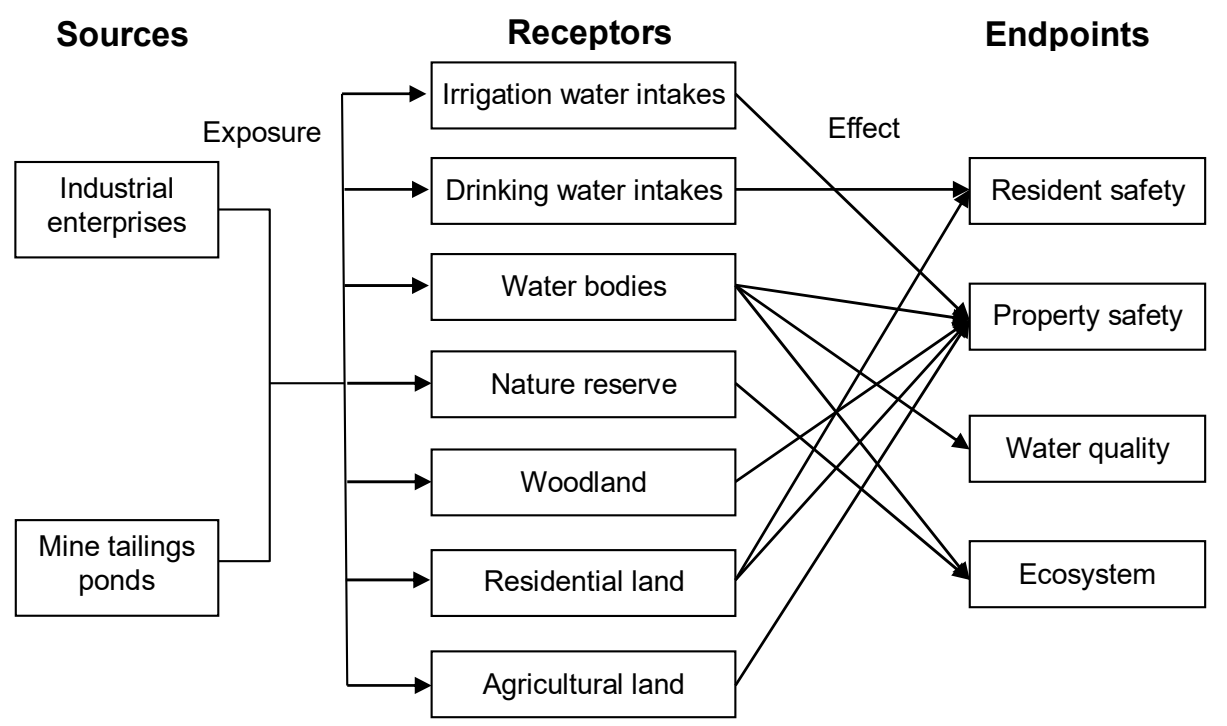

Figure 1. Conceptual model of the WAPRA.

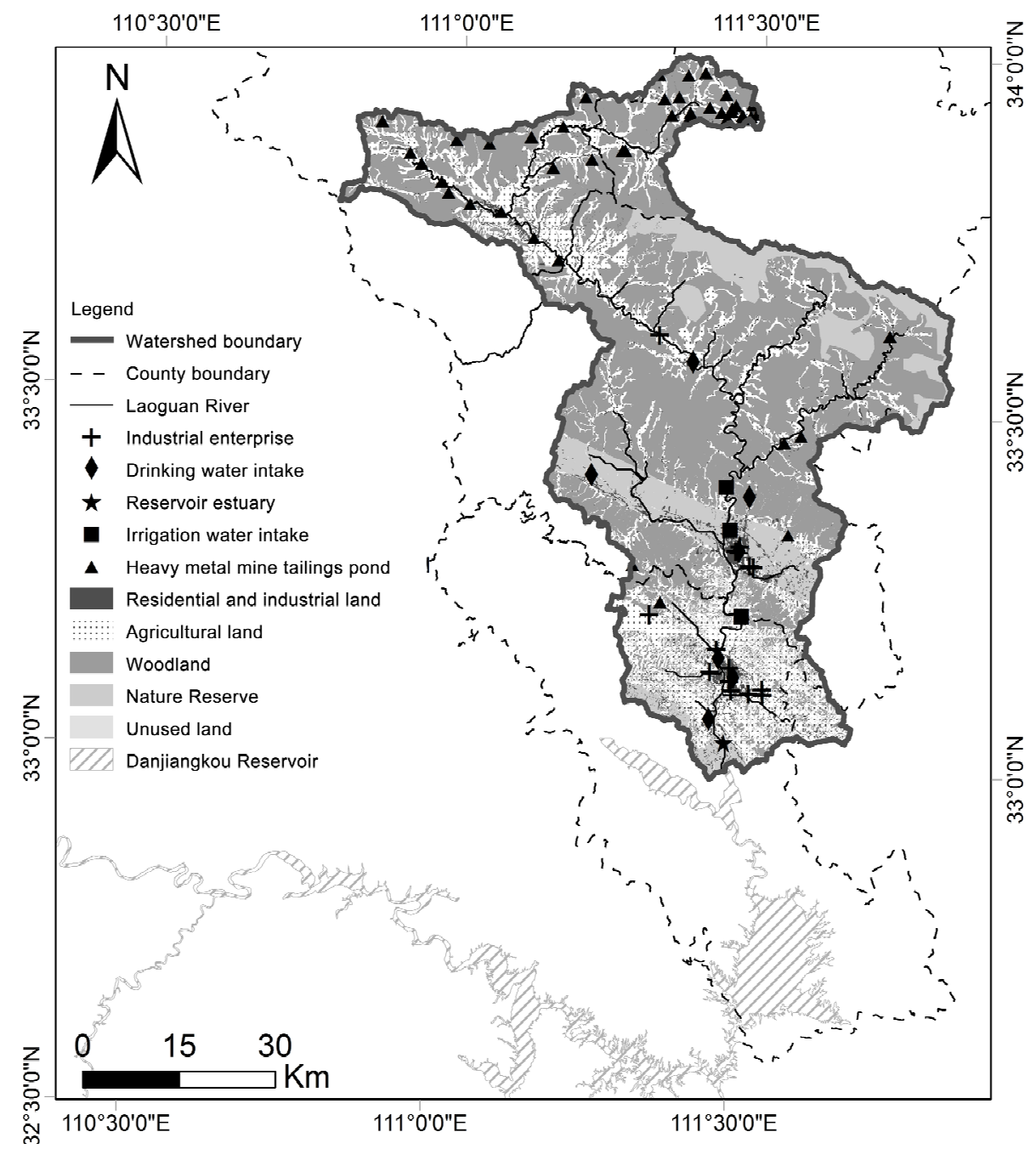

Figure 2. Laoguan River basin and Danjiangkou Reservoir. 
tailings ponds. The midstream sub-catchment, which is mostly located in Xixia County, contains a large nature reserve alongside areas of highly developed manufacturing industries. Xichuan County occupies the downstream reaches of the watershed and contains the primary water source for the South-toNorth Water Diversion Project. Laoguan River is the main tributary feeding the Danjiangkou Reservoir, the source of the middle route of South-to-North Water Diversion Project. Hence, Laoguan River has a major influence on the water security and quality of Danjiangkou Reservoir.

\subsubsection{Data Sources}

The risk sources for mine tailings ponds have been mostly derived from an unpublished investigation into tailings ponds in Henan Province conducted in 2012. Supplementary information was obtained by means of a field investigation undertaken during the summer of 2013. Data on the majority of the industrial enterprises have been extracted from the National Inspection Records of Environmental Risk and Chemicals in Enterprises of Key Industries (Environmental Risk Inspection for short). The Environmental Risk Inspection was completed nationwide in 2010. We also updated the records on industrial enterprises using data from a field investigation conducted in the summer of 2013. A total of 61 risk sources were identified across the Laoguan River basin, 46 of which were mine tailings ponds (labelled T1 T46) and 15 were industrial enterprises (labelled E1 $\sim$ E15). Specific details of the stressor sources (Section 2.2.2) have been derived from the foregoing records or field investigation results.

Risk receptors have been primarily derived from the landuse map and our data collection results from 2012. The 1:150000 scale land-use map of Laoguan River basin (see Figure 2) was interpreted from the remote sensing image obtained by Landsat-7 in July 2009, and downloaded from the China Centre for Resources Satellite Data and Application (CRESDA) at $30 \times 30 \mathrm{~m}$ spatial resolution, with UTM map projection and WGS_84 earth coordinates. Information on the local population, locations and services (relating to water intakes, crop categories, local water environmental functions, and the locations and spatial areas of nature reserves) was obtained from data collected by the civil authorities of the four administrative counties in 2012. Risk receptors in Laoguan River basin were finally grouped as follows: reservoir estuary (RE); drinking water intake (DW); irrigation water intake (IW); water body (WB); residential land $(\mathrm{RL})$; nature reserve $(\mathrm{NR})$; agricultural land (AL); and woodland (WL).

Other spatial data (i.e., $90 \times 90 \mathrm{~m} \mathrm{DEM}$, the water system digital map, and administrative boundary locations) were also obtained from CRESDA. Additional hydrological data were provided by local hydrographic stations. Spatial locations of risk sources, risk receptors, rivers and the reservoir were extracted and mapped using GIS tools (see Figure 2).

\section{Results}

\subsection{The Watershed Risk Map}

The entire watershed has been divided into 10 sub-water- sheds as assessment regions (labelled RR1 RR10, see Figure 3). The upstream, midstream, and downstream areas comprise the following watersheds: RR1 $\sim$ RR3, RR4 RR8, and RR9 $\sim$ RR10, respectively. All 61 risk sources and 8 categories of receptors (see Section 2.3.2) have been taken into account in four risk assessment endpoints of resident safety (RS), property safety (PS), water quality (WQ), and ecosystem health (EH). Figure 3 shows the overall ranking risk map for Laoguan River basin. Sub-watersheds RR2, RR3, and RR9 are at most risk of water accidental pollution. Sub-watersheds RR1 and RR4 are at high risk. RR8 and RR10 are at medium risk. And RR5, RR6, and RR7 are at low risk. It is obvious that whereas the upstream and downstream reaches are exposed to higher risk, the midstream reach is less at risk. Figure 4 presents the sum risk scores by each possibly existing receptor in each subwatershed. Figure 5 shows the sum risk scores by each assessment endpoint in each sub-watershed. By interpreting these figures and the background assessment information, three important findings have been obtained in addition to the identification of areas at high and very high risk.

Most significant sources. Heavy metal mine tailings ponds, especially in RR2 (31 of a total of 46 tailings ponds), provide the majority of most significant risk sources (see Figure 2). These mine tailing ponds pose considerable threats to areas in which they are located (e.g., RR1 and RR2) and nearby areas (e.g., RR4 and RR3, the threat coming from RR1 and RR2), but not to the far midstream and downstream reaches (see Figure 3 ). The most hazardous sources to the downstream sub-catchment and the Dangjiangkou Reservoir arise from industrial enterprises located in areas RR8, RR9 and RR10.

Most vulnerable receptors. Across the entire watershed, water bodies comprise the most vulnerable receptors and are

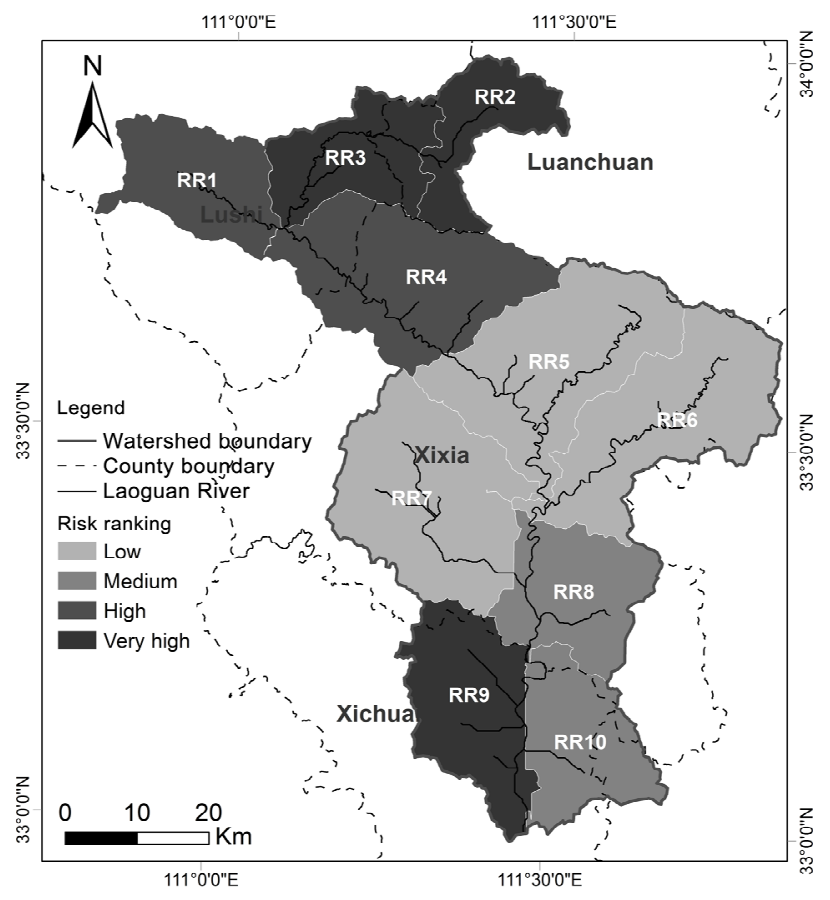

Figure 3. Risk ranking map for sub-watershed RR1 $\sim 10$. 
associated with the majority of high risk scores presented in Figure 4. In the upstream sub-catchment, the greatest vulnerability is experienced in the RR2 area by local residential land and irrigation water intakes. Another vulnerable zone comprises the water body in RR3, which is prone to potential pollution passed down from tailings ponds of RR1 area. In the downstream sub-catchment, especially in the RR9 area, the reservoir estuary and drinking water intakes are most vulnerable to accidental water pollution events.

Significantly impacted endpoint. Figure 5 indicates that water quality is the most significantly impacted endpoint, especially in the RR2, RR3, RR4, and RR9 areas. In upstream areas, property safety is another endpoint significantly impacted upon by accidental pollution from heavy metal mine tailings ponds. Resident safety must be a priority, especially in the RR2 and RR9 areas.

In addition, RR1 and RR3 share similar local stressors and receptors, while RR3 experiences the higher risk passed down from RR2 along the river. RR4 is also susceptible to transferred risk but less so than RR3. Areas RR5 to RR7 are at low risk having almost no local stressors and being located far from the upstream threats. Several hazardous industrial enterprises located in RR8 and RR10 raise the risk to medium level, where the receptors are far less vulnerable than the reservoir estuary and drinking water intakes in RR9.

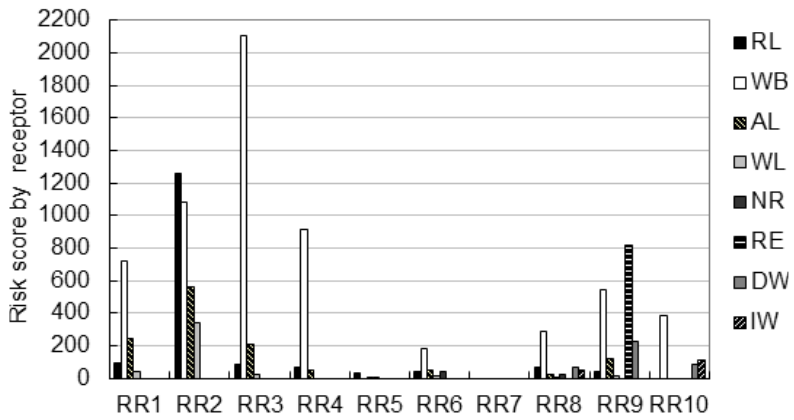

Figure 4. Risk score by each receptor for sub-watersheds $\mathrm{RR} 1 \sim 10$. RL is residential land; WB is water body; $\mathrm{AL}$ is agricultural land; WL is woodland, NR is nature reserve; $\mathrm{RE}$ is reservoir estuary; DW is drinking water intake; IW is irrigation water intake.

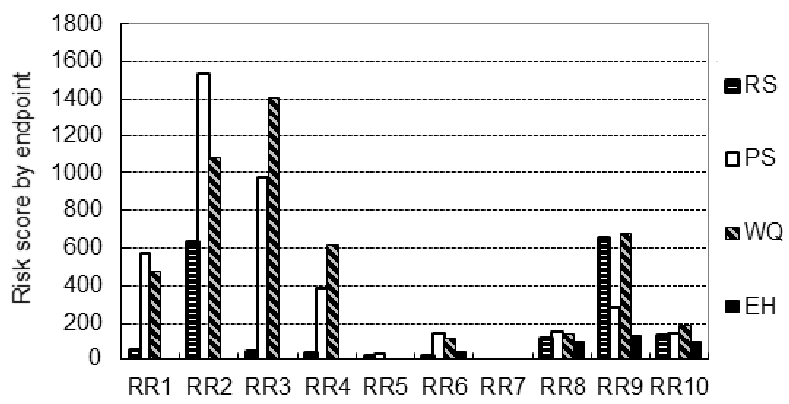

Figure 5. Risk score by each endpoint for sub-watersheds $\mathrm{RR} 1 \sim 10$. RS is resident safety; PS is property safety; WQ is water quality; and $\mathrm{EH}$ is ecosystem health.

\subsection{Uncertainty Analysis}

Regions RR5, RR1, and RR9 are selected for uncertainty analyses, because they are representative of assessment regions at low, high, and very high risk levels, respectively. Figure 6 $(a, b, c)$ presents the results of the uncertainty analysis. The means of the distributions are similar to the corresponding assessment results, implying that the uncertainty of method of calculation has not changed the order of the risk results. The narrower range of the distribution suggests more confidence in the risk prediction, for which RR5 (low risk region) has the least uncertainty. The uncertainty is higher for the upstream and downstream sub-watersheds compared to the middle reach, due to the larger number of risk components (i.e. sources, receptors, and endpoints) involved. The frequency distributions for RR1 and RR5 are left-skewed, suggesting that the risk level may have been overestimated. However, the frequency distri-

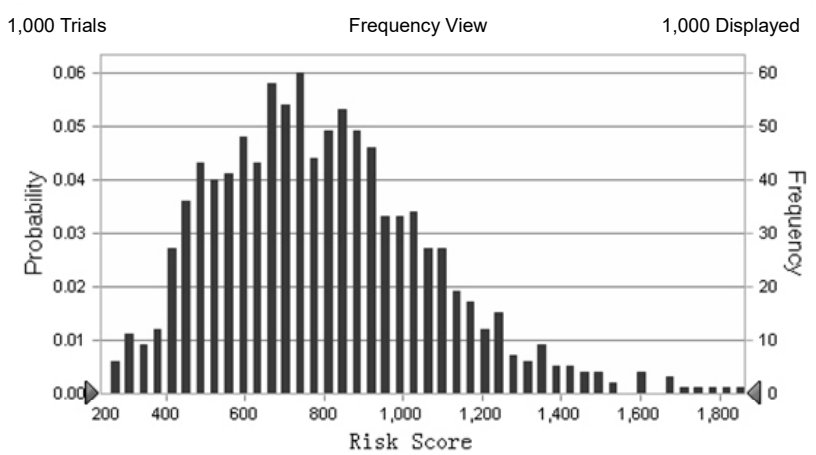

(a) RR1

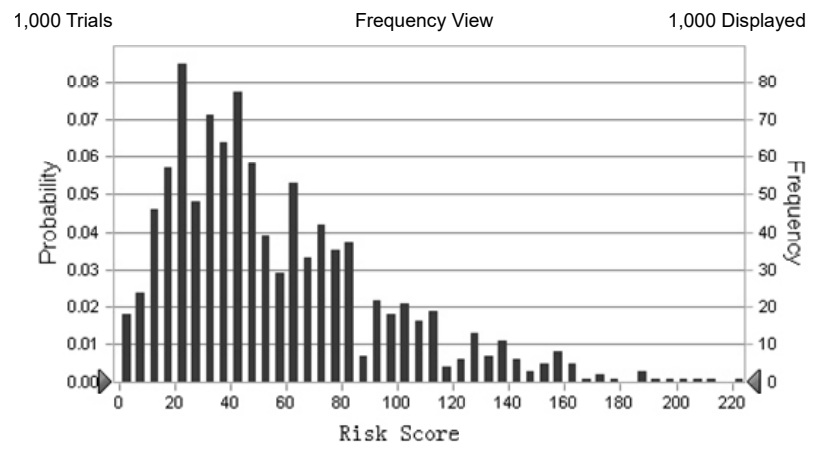

(b) RR5

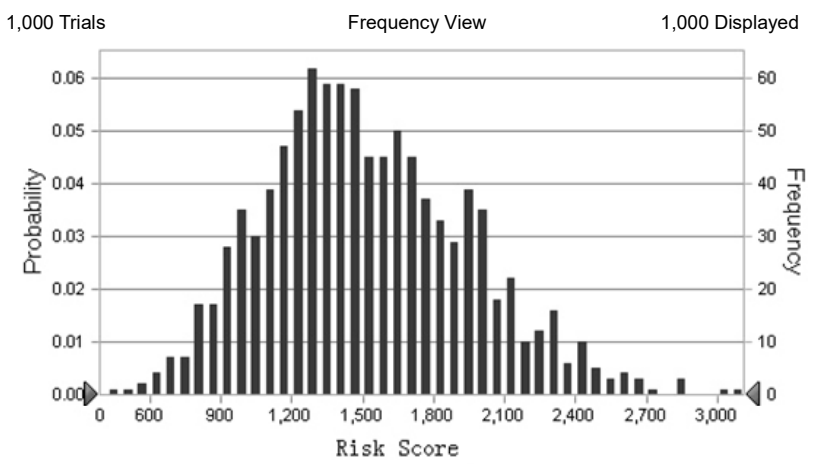

(c) RR9

Figure 6. Uncertainty analysis result: probability distribution. 
bution for RR9 follows a quasi-normal curve, suggesting a relatively accurate estimate of risk level.

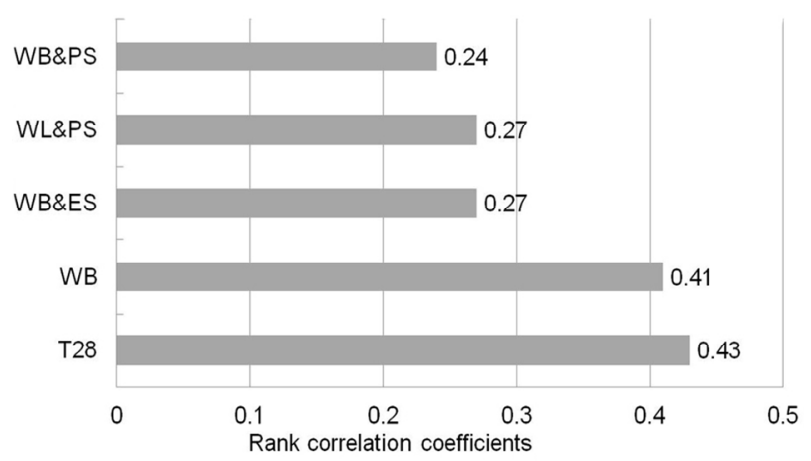

(a) RR1

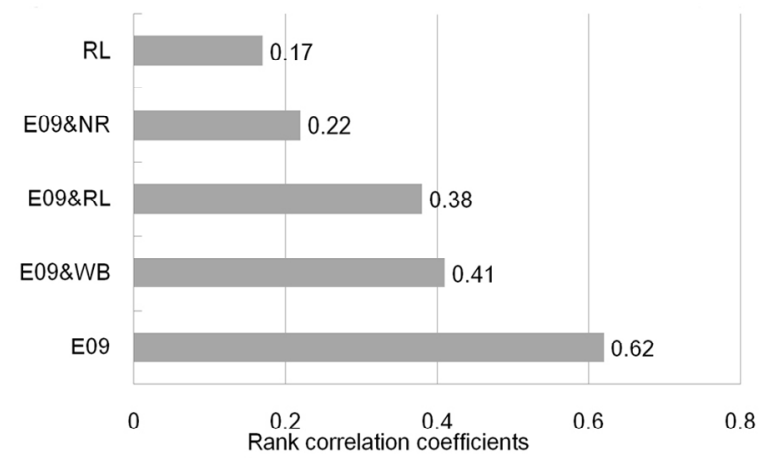

(b) RR5

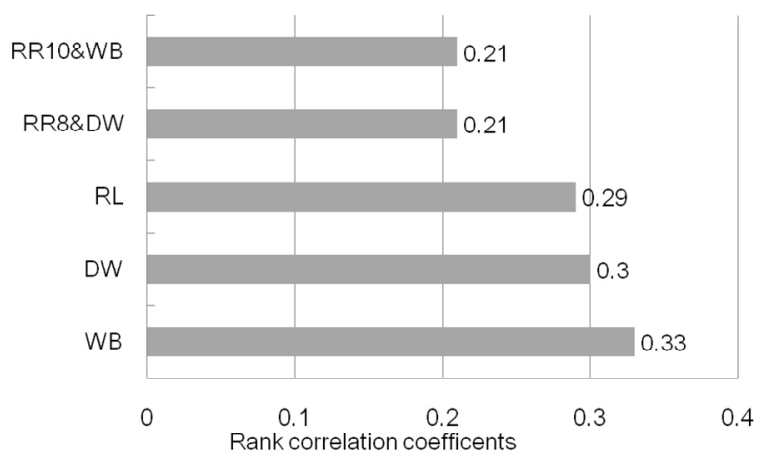

(c) RR9

Figure 7. Rank correlation coefficients. WB is water body; RL is residential land; DW is drinking water; T28 is a mine tailing source; E09 is a chemical enterprise source; WB \& PS and WB \& ES are effect filters of water body to property safety and ecosystem health, respectively; WL \& PS is an effect filter of woodland to property safety; E09 \& NR, E09 \& RL, and E09 \& WB are exposure filters of the chemical enterprise E09 to nature reserve, residential land, and water body, respectively; RR10 \& WB is the exposure filter of No. 10 sub-catchment to water body; RR8 \& DW is the exposure filter of the No. 8 sub-catchment to drinking water.

The highest five rank correlation coefficients in RR1, RR5 and RR9 are displayed in Figure $7(a, b, c)$. For RR1, the highest rank correlation is due to mine tailing source T28 (0.43), followed by receptor WB (0.41), then the effect filters. For RR5, the highest rank correlation is due to the chemical enterprise source E09 (0.62), followed by exposure filters, then receptors. The risk sources are responsible for a major contribution to uncertainty regarding the two sub-watersheds, RR1 and RR5. For RR9, uncertainty mainly derives from the receptor scores and exposure filters.

\section{Discussion}

The Watershed-scale Accidental Pollution Risk Assessment (WAPRA) has transferred the idea of integrating "sourcehabitat-impact" risk routes to a large regional scale watershed. Within the framework of a Relative Risk Model (RRM), the WAPRA concentrates on environmental risk and so is purely concerned with contaminant stressors, habitats susceptible to accidental water pollution, and the corresponding impacts. WAPRA enables watershed-scale risk assessments to be undertaken involving complicated interrelationships of multiple sources, habitats, and impacts where cascading and cumulative effects are embedded (see Section 2.1). Furthermore, WAPRA has improved the process of ranking sources (stressors) using multiple criteria which make detailed use of the available source information. The approach is capable of providing quantitative information by which to identify the most significant risk sources in a watershed, which can enhance assessment accuracy. Another advantage of WAPRA is that it provides increased transparency in estimating exposure by means of a simple instantaneous water quality model, which makes screening the risk routes more efficient and assignment of exposure filters more reasonable.

Compared with Liu et al. (2013) previous regional risk assessment, WAPRA adopts a simpler multiple criteria approach by which to evaluate the risk source hazards, though the risk multiplication formula of hazard and vulnerability essentially remains unchanged (see Equation 3). The new method can discriminate each single "source-habitat-impact" risk route and so clarify the interrelationships between multiple sources and multiple receptors which were both tangled within a single assessing region in the previous study by Liu et al (2013). Importantly, WAPRA offers a more comprehensive risk assessment whereby the stressor hazards are passed from upstream to downstream sub-watersheds. This was not achieved in the previous study, where only inner sources of stressors were evaluated within a single assessment region.

The WAPRA process has been presented in a standardized fashion, with strict standards and criteria incorporated into the risk ranking procedure (see Section 2.2), the aim being for this improved method to achieve wide acceptance once further applications of watershed risk assessment have been undertaken. In the future, it will be possible to compare directly the risk levels for different watersheds to which the WAPRA have been applied once common ranking criteria have been established.

Application of WAPRA to the Laoguan River basin study area has shown that the assessment results are operable and applicable. At the time of writing, it is vital that acute water 
pollution risk be mapped for the whole Danjiangkou Reservoir watershed, given that it commenced supply of drinking water via the middle route of the South-to-North Water Diversion Project on December 12, 2014. Successive applications of WAPRA have made it possible to obtain the whole risk map for the Danjiangkou Reservoir basin. From the resultant risk map, the upstream sub-catchment areas, RR2 and RR3, are at very high risk due to proliferation of mine tailings ponds in these regions, which could potentially release heavy metals and other toxic chemicals into the river. The downstream subcatchment area RR9 is also at very high risk because it contains some of the most vulnerable receptors (i.e. reservoir estuary and drinking water intakes). The WAPRA assessment identified most the significant pollutant sources, most vulnerable receptors, and the most significantly impacted endpoints, all of which are helpful for decision makers involved with watershed environmental risk management for the Laoguan River. Different spill scenarios simulated typical pollution incidents from which response measures were derived for early warning and emergency plans for Laoguan River, covering the whole watershed of Danjiangkou Reservoir. The analysis shows that upstream mine tailing ponds pose the biggest threats to the whole watershed. Therefore, cleanup of abandoned mines and reinforcement of tailing ponds are strongly recommended to improve the safety of the Laoguan River watershed. For receptors, the safety of local residents in RR2 is of prime concern for risk management. Countermeasures to mitigate against pollution from tailings ponds are needed where residential areas may be affected. For example, residents may have to be relocated if necessary. The reservoir estuary, a key point in the middle route of the South-to-North Water Diversion Project, is threatened by several hazardous industrial enterprises and one heavy metals tailings pond. In that case, it is recommended that decision makers prioritize the key options and take all necessary countermeasures, such as reinforcing the level of risk management, reducing the stock quantities of hazardous substances, and even relocating or closing certain enterprises, to ensure the risk remains within safe limits.

It should be noted however, that WAPRA may have overestimated the risk in certain areas of the Laoguan River watershed, as indicated by the results of the uncertainty analysis. One reason for this is that extreme situations are usually considered while ranking the sources or receptors. Therefore any single "source-habitat-impact" may be given the maximum risk ranking. Another reason derives from the idealised integration of risk routes, which may lead to additional risk routes increasing the spatially cumulative risk in a watershed. These two reseasons may lead to overestimation of the risk.

\section{Conclusions}

A WAPRA approach was proposed for accidental water pollution risk assessment at watershed-scale. The approach involves the integration of "source-habitat-impact" using a ranking system based on specific rules for watershed-scale risk assessment. A set of common criteria was constructed to rank the hazards from different sources and the vulnerability of receptors. A simple instantaneous water quality model was uti- lized to help quantify the exposure probability. WAPRA was found to have the advantage of tackling complicated interrelationships of multiple sources, multiple receptors, and multiple impacts. By embedding cascading effects and spatially cumulative effects, a reasonable assessment was achieved at watershed-scale. The resultant risk map for the case study of Laoguan River basin indicated that the upstream and downstream sub-catchments were suffering higher risk than the midstream sub-catchment. The most significant pollutant hazard sources are (heavy metal) mine tailings ponds mostly located in the mountainous upstream areas. The most vulnerable receptors involved the water environment, in particular the reservoir estuary and drinking water intakes. The study shows that specific countermeasures are required to address areas at high and very high risk, and where the most significant sources, and most vulnerable receptors are located. The results provide useful reference data for decision making scenarios informing risk prevention, incident preparedness strategies, and early warning systems essential for the safe water provision of the Southto-North Water Diversion Project. Overestimation of risk in the WAPRA would be overcome by improving the ranking criteria after progressive applications of watershed-scale risk assessments have been completed in the future.

Acknowledgments. This research was supported by the National Natural Science Foundation of China under grant no. 41271514 and the National Science \& Technology Pillar Program of China under grant no. 2011BAC12B02. The authors are grateful to the local Environmental Protection Bureau and Hydrographic Office for assistance regarding the case study of Laoguan River, Henan Province in China.

\section{References}

Administration of Quality Supervision, Inspection and Quarantine of People's Republic of China (AQSIQ) (2009). Identification of Major Hazard Installations for Dangerous Chemicals, GB 182182009, Beijing.

Cai, Y.P., Huang, G.H., Yang, Z.F., Lin Q.G., and Tan. Q. (2009a). Community-scale renewable energy systems planning under uncertainty-An interval chance-constrained programming approach. Renew. Sustain. Energ. Rev. 13, 721-735. https://doi.org/10.1016/ j.rser.2008.01.008

Cai, Y.P., Huang, G.H., Yang, Z.F. and Tan, Q. (2009b). Identification of optimal strategies for energy management systems planning under multiple uncertainties. Appl. Energ., 86, 480-495. https:// doi.org/10.1016/j.apenergy.2008.09.025

Chen, Q.Y., Liu, J.L., Ho, K.C., and Yang, Z.F. (2012). Development of a relative risk model for evaluating ecological risk of water environment in the Haihe River Basin estuary area. Sci. Total Environ., 420, 79-89. http://dx.doi.org/10.1016/j.scitotenv.2011.09.044

Environmental Protection Agency (U.S. EPA) (2003). Framework for Cumulative Risk Assessment, EPA/630/P-02/001F, Washington D.C..

Faggiano, L., de Zwart, D., García-Berthou, E., Lek, S., and Gevrey, M. (2010). Patterning ecological risk of pesticide contamination at the river basin scale. Sci. Total Environ., 408(11), 2319-2326. http://dx.doi.org/10.1016/j.scitotenv.2010.02.002

Fan, Y.R. and Huang, G.H., (2012). A robust two-step method for solving interval linear programming problems within an environmental management context. J. Environ. Inf., 19, 1-9. https://doi. org/10.3808/jei.201200203

Fan, Y.R., Huang, G.H., Baetz, B.W., Li, Y.P., and Huang, K. (2017). 
Development of a copula-based particle filter (coppf) approach for hydrologic data assimilation under consideration of parameter interdependence. Water Resour. Res., 53(6) https://doi.org/10.1002/ 2016WR 020144

Giupponi, C., Eiselt, B., and Ghetti, P.F. (1999). A multicriteria approach for mapping risks of agricultural pollution for water resources: The Venice Lagoon watershed case study. J. Environ. Manage., 56(4), 259-269. http://dx.doi.org/10.1006/jema.1999.0283

Gómez Gómez, C.M., and Pérez Blanco, C.D. (2012). Do drought management plans reduce drought risk? A risk assessment model for a Mediterranean river basin. Ecol. Econ., 76, 42-48. http://dx. doi.org/10.1016/j.ecolecon.2012.01.008

Gottardo, S., Semenzin, E., Giove, S., Zabeo, A., Critto, A., de Zwart, D., Ginebreda, A., and Marcomini, A. (2011). Integrated risk assessment for WFD ecological status classification applied to Llobregat river basin (Spain). Part I - Fuzzy approach to aggregate biological indicators. Sci. Total Environ., 409(22), 4701-4712. http:// dx. doi.org/10.1016/j.scitotenv.2011.07.050

Hu, E.B. (2009). Environmental Risk Assessment: Practical Technology Methods and Cases (2nd Ed.), Chinese Environmental Science Press, Beijing.

Huang G.H., and Cao M.F., (2011). Analysis of solution methods for interval linear programming. J. Environ. Inf., 17(2), 54-64. https:// doi.org/10.3808/jei.201100187

Huang, L., Wan, W.B., Li, F.Y., Li, B., Yang, J., and Bi, J. (2011). A two-scale system to identify environmental risk of chemical industry clusters. J. Hazard. Mater, 186(1), 247-255. http://dx.doi.org/ 10.1016/j.jhazmat.2010.10.117

Hunsaker, C.T., Graham, R.L., Suter II, G.W., O'Neill, R.V., Barnthouse, L.W., and Gardner R.H. (1990). Assessing ecological risk on a regional scale. Environ. Manage., 14(3), 325-332. http://dx. doi.org/10.2307/1941812

Jenson, S.K. and Domingue, J.O. (1988). Extracting topographic structure from digital elevation data for geographic information system analysis. Photogramm. Eng. Remote Sensing, 54(11), 15931600 .

Ji, U., Velleux, M., Julien, P.Y., and Hwang, M. (2014). Risk assessment of watershed erosion at Naesung Stream, South Korea. $J$. Environ. Manage., 136, 16-26. http://dx.doi.org/10.1016/j.jenvman. 2014.01.033

Landis, W.G. (2005). Regional Scale Ecological Risk Assessment: Using the Relative Risk Model, Washington D.C., CRC Press.

Landis, W.G. and Wiegers, J.A. (1997). Design considerations and a suggested approach for regional and comparative ecological risk assessment. Hum. Ecol. Risk Assess., 3(3), 287-297. http://dx.doi. org/10.1080/10807039709383685

Li, Y.P., Huang, G.H., and Chen, X., (2011). Planning regional energy system in association with greenhouse gas mitigation under uncertainty. Appl. Energ., 88, 599-611. https://doi.org/10.1016/j.ap energy.2010.07.037

Li, Y.P., Huang, G.H., Huang, Y.F., and Zhou, H.D., (2009). A multistage fuzzy-stochastic programming model for supporting sustainable water resources allocation and management. Environ. Model. Soft., 24, 786-797, https://doi.org/10.1016/j.envsoft.2008. 11.008

Liu, R.Z., Borthwick, Alistair, G.L., Land, D.D., and Zeng, W.H. (2013). Environmental risk mapping of accidental pollution and its zonal prevention in a city, Process Saf. Environ. Protection., 91(5), 397-404. http://dx.doi.org/10.1016/j.psep.2012.10.003

Macary, F., Morin, S., Probst, J.-L., and Saudubray, F. (2014). A multi-scale method to assess pesticide contamination risks in agricultural watersheds. Ecol. Indicators., 36, 624-639. http://dx.doi.org/ 10.1016/j.ecolind.2013.09.001

Ministry of Environmental Protection of the People's Republic of China (2004-2013). China Environment Bulletin 2004-2013, P. R.
China MEP, Beijing.

Ministry of Environmental Protection of the People's Republic of China (China MEP) (2014). Guidebook for Environmental Risk Assessment of Accidents in enterprises, P.R. China MEP, Beijing.

Mutekanga, F.P., Visser, S.M., and Stroosnijder, L. (2010). A tool for rapid assessment of erosion risk to support decision-making and policy development at the Ngenge watershed in Uganda. Geoderma, 160(2), 165-174. http://dx.doi.org/10.1016/j.geoderma.20 10.09.011

National Response Center (2014). National Response Center (NRC) incident reports from 2004-2013. http://cgmix.uscg.mil/NRC/ (accessed jun. 19, 2014).

Petrosillo, I., Vassallo, P., Valente, D., Mensa, J.A., Fabiano, M., and Zurlini, G. (2010). Mapping the environmental risk of a tourist harbor in order to foster environmental security: Objective vs. subjective assessments. Mar. Pollut. Bull., 60(7), 1051-1058. http: //dx. doi.org/10.1016/j.marpolbul.2010.01.021

Saaty, T.L. (1980). The Analytic Hierarchy Process, McGraw-Hill, New York.

Sadiq, R. and Husain, T. (2005). A fuzzy-based methodology for an aggregative environmental risk assessment: a case study of drilling waste. Environ. Model. Software., 20(1), 33-46. http://dx.doi.org/1 0.1016/j.envsoft.2003.12.007

State Administration of Work Safety of P.R.C. (SAWS) (2006). Safety Technical Regulations for the Tailings Pond, AQ2006-2005, Beijing.

State Council of the People's Republic of China (SC) (1994). The Natural Reserve Regulations of P.R. China, Beijing.

State Environmental Protection Agency of the People's Republic of China (China SEPA) (2002). Environmental quality standards for surface water, P. R. China SEPA, Beijing.

Suter II G.W. (1990). Endpoints for regional ecological risk assessments, Environ. Manage., 14(1), 9-23. http://dx.doi.org/10.1007/B F02394015

Suter II G.W. (2007). Ecological Risk Assessment, (2th Ed.), CRC Press, Boca Raton.

Uricchio, V.F., Giordano, R., and Lopez, N. (2004). A fuzzy knowledge-based decision support system for groundwater pollution risk evaluation. J. Environ. Manage., 73(3), 189-197. http://dx.doi. org/10.1016/j.jenvman.2004.06.011

Walker, R., Landis, W., and Brown, P. (2001). Developing a regional ecological risk assessment: A case study of a Tasmanian agricultural catchment. Hum. Ecol. Risk Assess., 7(2), 417-439. http://dx. doi.org/10.1080/20018091094439

Wang, L.Z., Chen, Z.F., and Lu, Y.S. (1998). Progress of accidental pollution risk management. Adv. Environ. Sci., 6 (3), 14-23.

Wang, L., Huang, G., Wang, X., and Zhu, H. (2018). Risk-based electric power system planning for climate change mitigation through multi-stage joint-probabilistic left-hand-side chance-constrained fractional programming: a canadian case study. Renew. Sustain. Energy Rev., 82, 1056-1067. https://doi.org/10.1016/j.rser.2017.09. 098

Wickham, J.D. and Wade, T.G. (2002). Watershed level risk assessment of nitrogen and phosphorus export, Comput. Electron. Agric., 37(1-3), 15-24. http://dx.doi.org/10.1016/S0168-1699(02)00117-5

Wiegers, J.K., Feder, H.M., Mortensen, L.S., Shaw, D.G., Wilson, V.J., and Landis, W.G. (1998). A regional multiple-stressor rankbased ecological risk assessment for the Fjord of Port Valdez, Alaska. Hum. Ecol. Risk Assess., 4(5), 1125-1173. http://dx.doi.org/ 10.1080/10807039891285036

Yi, Y.J., Yang, Z.F., and Zhang, S.H. (2011). Ecological risk assessment of heavy metals in sediment and human health risk assessment of heavy metals in fishes in the middle and lower reaches of the Yangtze River basin. Environ. Pollut., 159(10), 2575-2585. $\mathrm{http} / / / \mathrm{dx}$. doi.org/0.1016/j.envpol.2011.06.011 